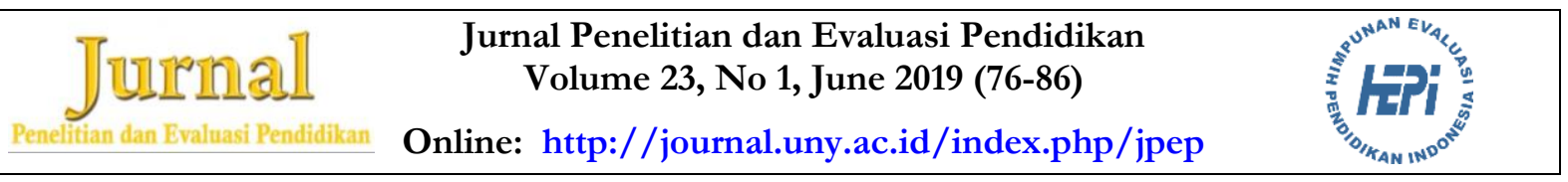

\title{
CHINA'S K-12 TEACHER QUALIFICATION SYSTEM
}

\author{
Dani Surya Lee \\ Southwest University, Chongqing China
}

\begin{abstract}
A strict teacher qualification system is vital to ensure a steady stream flow of high-quality human resources. In 1993, the People's Republic of China established the Teacher Law demanding that teachers must have legal status and qualifications. It has put into effect a system of qualification that could determine the readiness of K-12 teacher candidates to be practitioners of education. This country's teacher qualification system has experienced changes and adaptations until it has reached the current form in 2016's Teacher Qualification Examination, as more than a tool merely for formality or evaluation of rote learning, but an actual assessment of pre-service teachers' knowledge and abilities to conduct classroom teaching in authentic settings. This paper introduces this qualification examination system, while also mentioning some important and distinguishable aspects of teachers' situations in China, in the hope that it will shed some light on how this Asian giant is currently conducting its education.
\end{abstract}

Keywords: teacher qualification; $K-12$ teachers; education in China

Permalink/DOI: http://dx.doi.org/10.21831/pep.v23i1.24065

\author{
Contact Dani Surya Lee \\ danilee009@hotmail.com \\ - Faculty of Education, Southwest University, Chongqing \\ No. 2 Tiansheng Road Beibei District,Chongqing 400715, P.R. China
}




\section{Introduction}

Teacher quality plays more roles in affecting student achievement than any other school factors. Effective teachers may enable students to overtake their peers who were learning from less effective teachers. On the other hand, learning with poor-quality teachers has a long-lasting residual effect, which may be problematic to compensate in later grades even when studying under effective teachers (Looney, 2011).

Teachers must possess the required knowledge and skills. It is a general requirement that is probably the same in every part of the world, albeit different specifics. As Looney (2011) states, high-quality teachers are intellectually and verbally able; have good knowledge on the subjects they are teaching; are skilled in many diverse teaching methods; and are skilled assessors of their students. Chinese scholars and researchers have also stated that teachers should have the corresponding vocational knowledge, as well as the education and teaching skills concerning teaching design, teaching implementation, and teaching evaluation, and also able to correctly use them in conducting teaching practice (Cheng, 2016; Fu, 2003; Han, Zhong, Liang, Peng, \& Chen, 2017). These skills must be continuously enhanced with considerations towards teaching practice aspects such as subject management, lesson preparation, class management, feedback reflection, etc. (Ministry of Education of the People's Republic of China, 1993).

On the other hand, teachers must be mentally healthy. Vesely, Saklofske, and Leschied (2013) insist that Emotional Intelligence (EI) is critical in contributing to the prevention of occupational stress and burnout while improving a teacher's classroom management, therefore, helpful in mitigating the effect of stress. Cheng (2016) also argued that a teacher must own a sense of professional ethics and psychological literacy which must come from a healthy mind.

The People's Republic of China is a nation growing rapidly. Its economic development is undeniable and is the subject of many discussions and research. However, its development cannot be separated from how it conducts education, which, unfortunately, received very little attention, especially in how it selects its primary school teachers.

Like most countries, China has adopted a nine-year compulsory education system, including infant school education, primary education, secondary education, and higher education (Ministry of Education of the People's Republic of China, 1986, 1995). Through this research, we hope to introduce China's K-12 teacher qualification system used to meet its demand for effective teachers, with a focus on the new teacher qualification examination. It is hoped that this paper may serve as a base of reference for future research, and for the practical development of teacher qualification as well.

\section{Research Method}

The instruments used are documentary analysis, expert discussions, and interviews. The documentary analysis comprises of a comprehensive literature study of English journals, Chinese journals, and relevant research reports. The interviews include discussions with two experts in the field of Chinese education - teachers of the Faculty of Education in a well-known university in China, as well as text-interviews with three Chinese teachers and teachers-in-training that have undergone the old or new teacher qualification exam. This paper serves as a qualitative research report where the phenomenon is first generally discussed with an expert, followed by collecting individual stories and extensive documentary analysis. Another discussion with an expert followed, and finally, the result, i.e., the qualification system, is reported chronologically in order to create a comprehensive report on how the teacher qualification method works in China.

\section{Findings and Discussion}

\section{Chinese Teacher Education}

At the beginning of the last century, China has already had specialized schools to train teachers, and teachers were treated as 
public officials, paid by the state. As China's population grew out of control, however, the state was unable to bear the huge cost of education. Minimizing educational costs, the extensive use of non-teacher graduates or non-academically qualified teachers occurs. After the adoption of a socialist market system in the 1990s, educational development was strongly influenced by market forces and had two striking features: quantitative growth and qualitative enhancement (Li, 2010).

In 1986, the state's teacher service system already started to provide different grades of professional teachers, along with the technical titles and requirements. In 1993, the Teacher Law established a statutory teacher qualification system, demanding that teachers must have legal status and qualifications. This system became the national implementation of a statutory career permit system. According to this law, teachers who had not received professional education to teach must enroll in a professional academic training institution and obtain the certificate of accreditation. The Chinese Ministry of Education (MoE) (2009) published its English version of educational laws, including Teacher Law.

The categories and proportion of curriculum structure of most normal schools in China (Chen, 2014) are: (1) Public courses, e.g., politic, physical education, English, etc. This category accounted for approximately 15\%. (2) Pedagogy courses, e.g., theories of education, theories of psychology, the practice of education, etc. accounted for approximately 6 to $10 \%$. (3) Professional (or discipline) courses, according to each student's preference. This category accounted for approximately $70 \%$. (4) Fieldwork, or education practice for six to eight weeks.

In 2001, the state launched a fully implemented teacher qualification system through a provincial qualification examination. In 2012, the Ministry of Education gradually abolished the provincial Teacher Qualification Examination and began to implement the national Teacher Qualification Examination system with a distinguishable content and procedure, from mere rote learning to a more authentic setting of teaching practices (Liu \& Bai, 2016; Shi, 2017). The newest change, however, was in 2015 when the exam was made a mandatory requirement even for graduates of normal schools, and in 2016 when the content and the process were changed significantly again to emphasize actual teaching ability in classrooms (Cheng, 2016; Zeng, 2016).

There is a very distinct requirement in China for teacher qualification. After their graduation from normal schools, teacher candidates must apply and pass the teacher qualification examination given by or acknowledged by the state, and obtain the accreditation in the corresponding level and subject from the state's accreditation system for teachers (Fu, 2003; Gao, 2005).

To apply for the qualification examination, applicants must first already have obtained the necessary academic qualifications. The following is an example from the website of Chongqing Shi Jiaoyu Kaoshi Yuan [Chongqing Educational Examination Institute] (2017): Graduate of an infant normal school, college graduate or higher for kindergarten; college graduate or higher for primary school teachers; and, bachelor's degree or above for junior and senior high school.

However, in fact, the demand is much higher than this. Most of today's teachers in China are at least 4-year graduates of normal schools or are universities graduates, and lots of them have master degrees. Part of this unwritten requirement was established due to the tight competition of workforce in China. The higher the degree, the higher the possibility of securing a good job or position. Another thing to consider is that it is not actually mandated for people who want to work as a teacher to have a normal school graduation certificate, but, the ownership of a certificate would give him/her a better chance in procuring a job in better schools.

\section{The Current Condition of Chinese Teachers}

In recent years, there is a significant improvement in the status of general K-12 teachers. China's MoE has formally written 
the education law that the whole society shall respect teachers. This regulation, however, has no practical use, as Chinese culture encourages the people to base respect on tangible aspects such as position, wealth, achievements, and seniority. Instead, the improvements in teachers' condition come from the increase in salary and other benefits.

The Teacher Law in China stated that the average salaries of teachers should not be lower than the average salaries of the local civil servants. Currently, K-12 teachers' average base salary is approximately between 36,000 to 45,000 RMB net annually (Mei, 2017). This number is a fixed amount within the total salary. In addition to the base salary, teachers' total salary generally include 3 elements as follow: Allowance for length of service, given as a part of the monthly total salary, amount to $60 \mathrm{RMB}$ per year of service (e.g., if a teacher has taught in a school for three years, then in the fourth year his monthly total salary will have an additional 180 RMB); in-class hourly salary, given as a part of the monthly total salary for hours they teach students in classrooms; and performance pay, given per semester and also annually, can amount near to $10 \%$ of the total salary. The tax rate for teachers does not differ from other professions and will be deducted from the monthly salary before given to the teachers.

Other than the four components of the salary mentioned above, teachers are also entitled to other benefits. For example, the State's required schools to give teachers pocket money called hongbao (lit. translated into "red envelope") on their birthdays with the sum of money as much as $100 \mathrm{RMB}$ as a symbol of consideration and good intention. There are also welfare benefits prescribed by the State; housing supports given by some schools, as well as the approximately three months of leave with pay in winter and summer vacations.

From our discussion with experts, we have found that an essential reform of teachers' welfare is the fact that now it is more dependent on the individual schools' policy instead of the State's in providing additional teacher benefits. There is, however, a decrease in teachers' welfare for some good schools (i.e., schools that has obtained higher accreditation). For example, before, good schools may give salary up to $10,000 \mathrm{RMB}$ for K-12 teachers, not including housing supports and other benefits, now there is no such privilege. This decrease is balanced by the State's law of a higher general salary for all teachers. An expert argued that even though the welfare seemed to decline at some schools, due to the broader spread of equality among teachers' salary, there is an increase in overall welfare.

However, the most attractive thing about being a teacher in China is job stability. There is basically no teacher layoffs, provided that they perform their duties as prescribed by the law. Among other things, political awareness and ideological level are crucial aspects of teacher evaluation in China. We have confirmed through our discussion with experts that fulfilling these two aspects would secure the position while failing would mean termination despite any achievements or success.

We can see from the discussion above that due to the improvement of the overall status of teachers, improved treatment, occupational stability, basically no laid-off, and other advantages, the attraction of being a professional educator in China has become more popular compared to the period before the qualification system based on the Teacher Law was established.

Challenges in the Teacher Aspect of Education

Even after the method of qualification was established, there were still some challenges to be faced in the teacher aspect of education. Fu (2003) listed some of these challenges. However, following the rapid development of China's education system, some of them have been currently welladdressed. Through our discussion with experts in China's education, we have triangulated whether currently these challenges have been addressed or not and whether they can be a cause for concern. 
$\mathrm{Fu}$ (2003) stated that many primary and secondary school teachers had not received vocational training. It is not true today. As the qualification exam has evolved to be closer to an authentic assessment that actually focuses on teacher's practical ability, it is almost impossible to pass the exam without proper vocational training. Fu says many teachers choose to learn some easy-to-obtain qualifications to improve academic level and meet academic requirements. The disciplines of what they have learned, however, is inconsistent with the subject they are or will be teaching. For example, Chinese literature graduates teaching physics, Politics graduates teaching English, Math graduates teaching computers. This problem still exists, especially in the rural area, but rare for higher education institutions (there are still some in universities, but they happen only between sub-divisions courses, not interdisciplines). Experts argued that it should not be a problem. In China, this issue is seen mainly in the primary and secondary level of education.

As the current Chinese teachers are well equipped to teach these basic subjects or disciplines, regardless of what their advance academic specialties are, the quality of the teaching and learning process should not be much influenced by it. In other words, if the teacher can master the new subjects and teach them effectively to the students, then he/she can still be considered an effective teacher despite his/her original subject credentials. Besides, $\mathrm{Fu}$ argued that there is an uneven number of teachers in rural areas compared to urban areas. It also currently still happens. However, through the discussions with experts, it is found that, currently, there is a trend that many teachers prefer to work in the rural area instead of the big cities, especially for older teachers. In the same province, teacher salary is more-or-less the same. The school location, whether it is in the urban or rural area, does not have any influence. The stress level and demand of the job, however, is obviously different. This equal level of salary plus a lower level of demand has increased the attraction of being a teacher in the rural area.
The Law Aspect of Teacher Requirement

In China, the law aspect of an educator's job is a truly vital one. Failure in obeying the law shall result in a restriction to obtain qualifications for teachers as well as the forfeit of already obtained qualifications.

Written in the law, teachers must abide by the constitution, laws and professional ethics; raise their ideological level and political consciousness, and carry out schools' teaching plans, fulfill teaching contracts and accomplish educational and teaching tasks (Ministry of Education of the People's Republic of China, 1995).

According to China's Ministry of Education in Teachers Law of the People's Republic of China, teachers can conduct educational and teaching activities and experiments, as well as engage in scientific research and academic exchanges, join professional academic societies and fully express their views in academic activities. They are also entitled to put forward opinions and suggestions regarding education, teaching, management of schools and the work of the administrative departments of education, and to participate in the democratic management of schools through congresses of teachers, staff and workers, or through other forms (Ministry of Education of the People's Republic of China, 1993).

It is important to remember that the expressions of their opinions and suggestions must always be parallel to the law of China and the view of the Chinese political party that they align themselves to. There are currently eight institutional minor-parties in China, but only one major party, which is the Communist Party of Chinese with the President of China as its General Secretary. Practitioners of the field stated that a teacher might choose not to align him/herself with any political party, but joining a party may give some advantages such as access to some jobs or positions that may otherwise be unavailable. Whether they are a member of a political party or not, however, expressing, supporting, or teaching the opposing views could still result in termination. 
In dealing with the students, according to the Teacher Law, teachers can guide students in their studies and development and evaluate their works and academic achievement. It is also emphasized in the law that the teachers are to be paragons of virtue and learning in terms of ideology i.e., (the State's) morality, culture, science, and technology, at the same time, pay attention to their individual differences, teach students on the basis of their aptitude and promote full development of students. Thus, from the discussion above, it is indicated that Chinese teachers must be able to guide students to balance their individualism's crea-tivity and nationalism at the same time, to make them grow but keep them in line, to inspire students to be brilliant, not for themselves, but for the good of the country as a whole.

\section{Teacher Qualification Examination}

Mandated tests measure the competence of teacher candidates by assessing their knowledge of best teaching practices and their knowledge of the skills which are needed for being an effective teacher (Goodman, Arbona, \& de Rameriz, 2008). Gao (2005) stated that China's teacher qualification system serves to improve the quality of teachers, and functions as an essential element to facilitate teacher standardization, as well in establishing teacher training and education.

China's MoE indicates clearly that all Chinese citizens within legal working age, who abide by the constitution and laws, take a keen interest in education, have sound ideological and moral character, possess a record of formal schooling as stipulated in the Teacher's Law and have passed the national teachers' qualification examinations may obtain qualifications as teachers.

National teacher qualification examination has become the only standard for obtaining K-12 teacher qualification (Cheng, 2016). Since 2015, all of those who apply for kindergarten, primary school, junior high school, senior high school, secondary vocational school teacher qualification, and secondary vocational school practice instructor qualification, are required to take the exam- ination. Even students of normal schools are no longer directly qualified as teachers after graduation and must take the exam as well. This requirement, however, does not influence graduates of normal schools before the rules were applied.

The professional titles of K-12 teachers engaging in compulsory education that can obtain through the qualification examination are classified into pre-school, primary, intermediate and senior (Zhongguo Jiaoshi Zige Wang [China's Teachers Qualification Network], 2008; Zhongguo Jiaoyu Kaoshi Wang [China Educational Examination Network], 2017). Each candidate can choose the exam classification according to the educational level where he/she is planning on teaching. By obtaining the pre-school qualification, teachers are qualified to teach in kindergartens; primary qualification is for primary schools; intermediate qualifications, junior high schools; and senior qualifications, senior high schools. Candidates need to pass the exam only once to work as an educator in the corresponding level (periodical evaluation or assessment process will take over afterward). A teacher that obtains a higher level of classification can also work in the level lower than his/her qualification, but not the other way around.

All Chinese citizens who abide by the constitution and laws, whether they are normal school or non-normal school graduates, may take the National Teacher Qualification Examination as a condition to procure the teaching positions. Zeng (2016) stated that the exams take place twice a year.

Gui (2014) argued that in the past, China's teacher qualification exam had only focused on "rote" ability of the test. It only examined the pedagogy and psychology aspect of teacher candidates without testing their subject knowledge and teaching abilities, which makes any professional person can apply for teacher qualification. However, now, the exam assesses applicants' practical knowledge and analytical thinking, instead of merely a simple memory ability. It gives the graduates of normal schools a huge advantage. 
Since 2016, there is a huge change in the way the examination is being conducted and the content of the examination (Zeng, 2016). The current examination is divided into two parts: written examination and interview examination. The participants have to grasp basic teaching knowledge and skills, as well as the corresponding knowledge of the discipline they want to teach (Chen, 2014; Han et al., 2017).

To prepare for the exam, candidates must familiarize themselves with two basic books: Theory of Education Examination and Principles of Educational Psychology Examination. These books are developed by the Personnel Division and Examination Center of the Ministry of Education, printed by East China Normal University Press. The books are publicly marketed, easy to obtain, affordable, and are distinguished into three levels: for primary school, middle school (junior and high school), and higher education teacher candidates. Many training centers offer courses and supplement books to prepare candidates for the exam, which also included the contents of the above mentioned two mandatory books.

In the new system of 2016, however, there is additional knowledge that candidates must master to pass the exam: the comprehensive quality of a teacher, teaching knowledge and ability, education regulations and policies, and teacher professional ethics. For primary and higher levels of qualification, candidates must also partake in one among a few subject-related exams according to their teaching focus, such Chinese language, and literature, mathematics, physics, or other subjects-related knowledge. All of these will be included in the written exam according to the level of qualification (Zeng, 2016).

There is also a significant reform in the examination nature. Before, the emphasis is on rote memorization of Educational Theories and Principles of Educational Psychology, the two books mentioned above. Now, although rote memorization of those principles still has its place, the national examination pays more attention to the comprehensive quality and practical ability, focusing on the candidates' ability to solve the problems of teaching practices. In the written exam, other than basic principles, the qualification process also focuses on specific case studies and the application of basic educational principles, so that the candidates in their daily work life are proven able to identify the problem, ask questions, and solve the problem. In the interview examination, the focus is on the candidates' classroom teaching designs, teaching practice, as well as incident handlings, contingencies and other aspects of a teacher's comprehensive ability (Cheng, 2016; Shi, 2017; Zeng, 2016).

Figure 1 explains the overall workflow of the National Teacher Qualification Exam. The following are the details concerning the individual parts, as described in Figure 1.

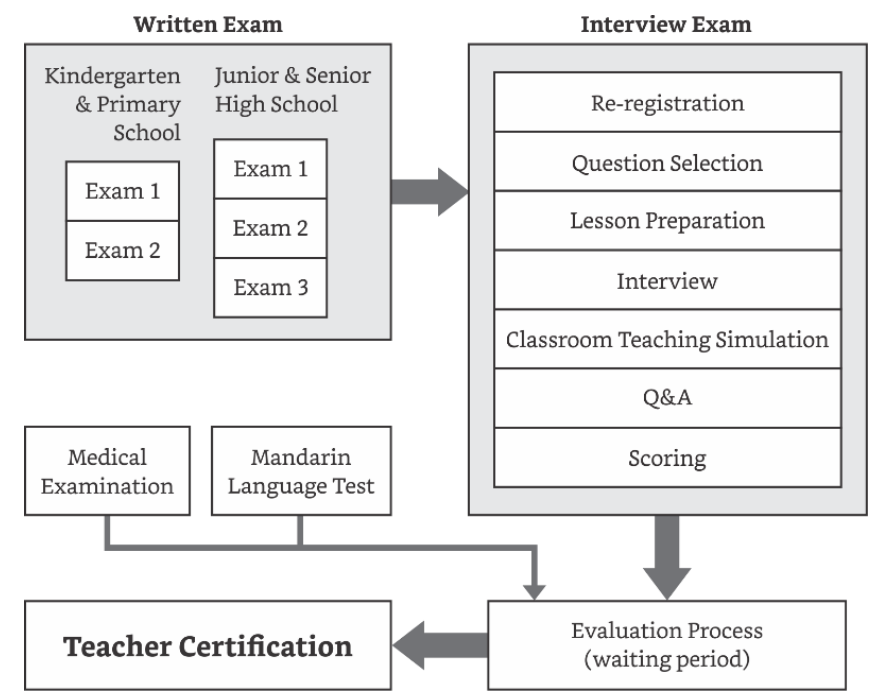

Figure 1. China's National Teacher Qualification Exam 


\section{Written Examination}

In the former version of the teacher qualification examination, Theory of Education and Principles of Educational Psychology have separate examinations, with separate outlines and knowledge points. The new exam does not separate pedagogy and educational psychology but integrates them into parts of the exam in the assessment process, which better reflects the real ability of the teacher candidates.

Table 1 describes the difference in the content of the written exam of different $\mathrm{K}$ 12 examination levels (Zhongguo Jiaoyu Kaoshi Wang [China Educational Examination Network], 2017). Pen and paper are used in the written examination. The allotted time is 120 minutes. The tests include multiple-choice questions, short answer questions, and essays. The content, other than theories, are questions concerning case analysis, the practice of principles, teaching and activity designs, case studies, etc.

Passing all exams within the written examination segment of the qualification process is the prerequisite to take the interview exam. There are 2 to 3 tests within this segment, depending on the level of qualification. If an applicant fails a test (or tests) in the written exam, then he/she can choose to make up for the failed test(s) in the next term. However, applicants must now pay attention that after the exam's reform in 2016, the result of the individual tests will be valid only for two years. The failure to pass the whole exam and obtain the certification within these two years will result in a total repetition of the whole process (Shi, 2017; Zeng, 2016).

\section{Interview Examination}

Structured interviews and multiple authentic assessment methods, such as lesson preparation and classroom teaching simulation, were employed in this segment. The main assessment covers the applicant's professional ethics, psychological quality, mental health, manners, speech and expressions, basic literacy of teaching and teaching design ability, implementation of the teaching plan, teaching evaluation ability, and other basic teaching skills. Further, Chongqing Shi Jiaoyu Kaoshi Yuan [Chongqing Educational Examination Institute] (2017) describes the workflow of the interview exam process of K-12 teacher qualification on their website. Each stage is described as follows.

\section{$\underline{\text { Re-registration }}$}

Candidates arrive on the site on time with the interview ticket and ID, then proceed into the waiting room. The ticket can be printed from the MoE Examination Center's website a week before the examination date.

\section{Question Selection}

Candidates $\log$ in the software. Then, they were given a randomly-selected topic by the computer, give confirmation, and then receive a printed copy of the topic.

Table 1. Content of the Written Exam of Different K-12 Levels of the Teacher Qualification Exam

\begin{tabular}{|c|c|c|c|c|}
\hline \multirow{2}{*}{$\begin{array}{c}\text { Level of } \\
\text { Examination }\end{array}$} & \multicolumn{3}{|c|}{ Written Exam } & \multirow{2}{*}{ Interview Exam } \\
\hline & Exam 1 & Exam 2 & Exam 3 & \\
\hline Kindergarten & $\begin{array}{l}\text { Comprehensive } \\
\text { Quality }\end{array}$ & $\begin{array}{c}\text { Teaching Knowledge } \\
\text { and Ability }\end{array}$ & 一 & $\begin{array}{c}\text { Education and } \\
\text { Teaching Practice } \\
\text { Ability }\end{array}$ \\
\hline Primary School & $\begin{array}{l}\text { Comprehensive } \\
\text { Quality }\end{array}$ & $\begin{array}{c}\text { Educational Teaching } \\
\text { Knowledge and } \\
\text { Ability }\end{array}$ & 一 & $\begin{array}{c}\text { Education and } \\
\text { Teaching Practice } \\
\text { Ability }\end{array}$ \\
\hline $\begin{array}{l}\text { Junior High } \\
\text { School }\end{array}$ & Comprehensive & Educational & $\begin{array}{l}\text { Subject Knowledge } \\
\text { and Teaching Ability }\end{array}$ & $\begin{array}{c}\text { Education and } \\
\text { Teaching Practice } \\
\text { Ability }\end{array}$ \\
\hline $\begin{array}{l}\text { Senior High } \\
\text { School }\end{array}$ & Quality & $\begin{array}{c}\text { Knowledge and } \\
\text { Ability }\end{array}$ & $\begin{array}{l}\text { Subject Knowledge } \\
\text { and Teaching Ability }\end{array}$ & $\begin{array}{c}\text { Education and } \\
\text { Teaching Practice } \\
\text { Ability }\end{array}$ \\
\hline
\end{tabular}




\section{Lesson Preparation}

The candidates go into the preparation room and then, using pen and paper, prepare a lesson plan. The duration of this period of preparation is 20 minutes.

\section{$\underline{\text { Interview }}$}

A panel of examiners randomly selects two questions from the question bank. Candidates answer both questions. The duration is five minutes.

\section{Classroom Simulation}

Candidates demonstrate their teaching ability in practice according to the prepared lesson plan. The presentation should be done within 10 minutes.

Q\&A

Examiners ask questions concerning the teaching demo. The duration is five minutes.

Scoring

Examiners give the candidates a comprehensive score for the whole process - success or failure. Then, the examiners submit the score into the interview evaluation system.

The board of examiners consists of three people, and are composed of experts from colleges and universities, as well as excellent teachers in primary and secondary schools and kindergartens. They are required to take provincial or higher educational examination institutions' training.

\section{Mandarin Language Test and Medical Examina- tion}

Mandarin Language Test acts to confirm the candidate's qualification, as there might be some teacher candidates whose daily language are still heavily influenced by their local dialects. The law of China stated that all teachers must teach using standardized Mandarin or Putonghua. For Mandarin Language teacher candidates, there will be a higher standard for this test. The Mandarin test can be taken in a different period from the qualification examination, even years before, but must be obtained before the qualification certificate can be given.

Physical test also acts to confirm the qualification. It is especially crucial for kindergarten teacher candidates. However, different from the language test, the physical test must be taken within six months apart from the qualification exam. Some municipalities even required a period no longer than three months.

\section{Evaluation of the Result and Certification}

The MoE will examine the result, and after a waiting period, candidates can know their scores and qualification through the internet. Scores for the individual tests of written examination will be kept for two years. The MoE will also provide the Teacher Qualification Examination Certificate.

Important to note that, according to the new regulation of 2016, this certification is valid for three years (Shi, 2017), means that if a candidate does not engage in the field of education within three years after he/she received the certificate, then the certificate will be invalid or expired.

\section{Conclusion}

In recent years, we can see a significant improvement in the status, job treatment, occupational stability, and other advantages for teachers in China. The country's qualification system has demanded more from teacher candidates than it used to be, but at the same time promises fair compensations for the fulfilling of those demands through a general increase in teachers' welfare.

Chinese National Teacher Qualification Examination has become the only standard for obtaining teacher qualification. It is divided into two parts: written examination and interview examination, and have different contents according to the level of qualifications. The focus of the written exam is comprehensive educational knowledge and case studies to test how the candidates would identify the problem, do the thought process, and solve the problem. The focus of the 
interview examination is on candidates' mental health, classroom teaching design, and preparation, as well as other teaching practice aspects that are related to the profession.

By improving the overall quality of normal school students, or K-12 teacher candidates, we are ensuring the quality of future school teachers. The implementation of the teacher qualification system in China provides an effective personnel system guarantee to direct effective and qualified future teachers into the proper places and positions in society. With the addition of the demand for Chinese teachers to teach their students to think not only of him/herself but of the whole country, this system would ensure the continuous stream of quality human resource to support the growth of the nation as the whole.

\section{References}

Chen, Q. H. (2014). Jiaoshi zige kaoshi zhidu gaige gei xiaoxue jiaoshi zhiqian peiyang dailai de tiaozhan yu jiyu [Challenges and opportunities brought by the teacher qualification examination system reform for primary school pre-service teacher training]. Jiaoshi Jiaoyu Luntan, (27), 54 56.

Cheng, Y. (2016). Jiaoshi zigezheng guokao dui xueqian jiaoyu zhuanye rencai peiyang de tiaozhan yu jiyu [The challenges and opportunities of the national teacher qualification exam for talent cultivation in pre-school education major]. Jiangxi Guangbo Dianshi Daxue Xuebao, (4), 89-91.

Chinese Ministry of Education. Teachers law of the People's Republic of China (2009). People's Republic of China. Retrieved from http://en.moe.gov. $\mathrm{cn} /$ Resources/Laws_and_Policies/20 1506/t20150626_191385.html

Chongqing Shi Jiaoyu Kaoshi Yuan [Chongqing Educational Examination Institute]. (2017). Chongqing shi 2017 nian shang bannian zhong xiaoxue jiaoshi zige kaoshi mianshi gonggao Primary and secondary school teacher qualification examination interview notice of Chongqing city for the first half of 2017]. Retrieved from http://www.ntce.cn/html1/report/1 704/932-1.htm

Fu, Y. (2003). Jiaoshi zhuanye hua jincheng de lishi huigu yujiaoshi zige zhidu de zhongyao zuoyong [The historical review of teacher specialization and the important role of teacher qualification system]. Chengdu Shifan Gaodeng Zhuanke Xuexiao Xuebao, (22), $41-43$.

Gao, K. (2005). Jiaoshi zige renzheng zhidu de zuoyong ji qi wanshan [The function and other excellence of teacher qualification system]. Zhiye Shikong, (4), 22-23.

Goodman, G., Arbona, C., \& de Rameriz, R. D. (2008). High-stakes, minimumcompetency exams: How competent are they for evaluating teacher competence? Journal of Teacher Education, 59(1), 24-39. https:// doi.org/10.1177/0022487107309972

Gui, W. L. (2014). Woguo jiaoshi zige kaoshi xinjiu bishi dagang duibi yu fenxi [Comparison and analysis of China's current and former teacher qualification written examination]. Kaoshi Yanjiu, (3), 86-91.

Han, C. H., Zhong, W. M., Liang, F., Peng, R., \& Chen, Z. L. (2017). Jiaoshi zige kaoshi tizhi gaige xia shifansheng mianlin de tiaozhan he yingdui cuoshi [Challenges for teacher-training school students and the countermeasures under the reform of teacher qualification examination system]. Jiaoyu Guancha, (6), 133-137.

Li, Y. (2010). Quality assurance in Chinese higher education. Research in Comparative and International Education, 5(1), 58-76. https://doi.org/10.2304/ rcie.2010.5.1.58 
Liu, D. M., \& Bai, Z. F. (2016). Jiaoshi zigezheng gaige beijing xie shifan jiaoyu zhuanye jiaoxue gaige de sikao [Reflections on the teaching reform of the education in teacher-training schools under the background of teacher qualification reform - study case of Yulin College]. Yulin Xueyuan, (26), 91-93.

Looney, J. (2011). Developing high-quality teachers: Teacher evaluation for improvement. European Journal of Education, 46(4), 440-455. https://doi.org/10.1111/j.14653435.2011.01492.x

Mei, F. (2017). Xiaoxue laoshi gongzi yiban duoshao [The general wages for primary school teachers]. Retrieved from http://www.yjbys.com/wage/ 251172.html

Ministry of Education of the People's Republic of China. Compulsory Education Law of the People's Republic of China (1986). Retrieved from http://en.moe.gov.cn/ Resources/Laws_and_Policies/20150 6/t20150626_191391.html

Ministry of Education of the People's Republic of China. Teachers Law of the People's Republic of China (1993). People's Republic of China. Retrieved from http://en.moe.gov.cn/ Resources/Laws_and_Policies/20150 6/t20150626_191385.html

Ministry of Education of the People's Republic of China. Education Law of the People's Republic of China (1995). People's Republic of China. Retrieved from http://en.moe.gov.cn/
Resources/Laws_and_Policies/20150 6/t20150626_191385.html

Shi, C. Y. (2017). Jiaoshi zige 'guokao' beijingxia youhua tijiao zhuanye rencai peiyang moshi yanjiu [A study on the model of optimizing talent training in physical education under the background of 'the national examination']. Jilin Tiуn Xueyuan Xuebao, (33), 90-93.

Vesely, A. K., Saklofske, D. H., \& Leschied, A. D. W. (2013). Teachers-The vital resource: The contribution of emotional intelligence to teacher efficacy and well-being. Canadian Journal of School Psychology, 28(1), 71-89. https://doi.org/10.1177/0829573512 468855

Zeng, H. (2016). Xin jiaoshi zigezheng 'guokao' de tedian ji zhongyao yingxiang fenxi [An analysis of the characteristics and important influence of the new teacher qualification certification]. Dangdai Jiaoyu Sbijian Yu Jiaoxue Yanjiu, (4), 230-231.

Zhongguo Jiaoshi Zige Wang [China's Teachers Qualification Network]. (2008). Jiaoshi zige tiaoli [Teacher certification regulations]. Retrieved from http://www.jszg.edu.cn/portal/ policy_regulation/whole_policy?id $=2$ 32

Zhongguo Jiaoyu Kaoshi Wang [China Educational Examination Network]. (2017). Kaoshi jieshao [Introduction to exams]. Retrieved from http:// www.ntce.cn/html1/folder/1507/11 81-1.htm 